Fig. 3 A typical strip of nickel-silver coated with two stripes of a gold-silvercopper alloy several microns thick. This material can then be stamped and formed into contact springs

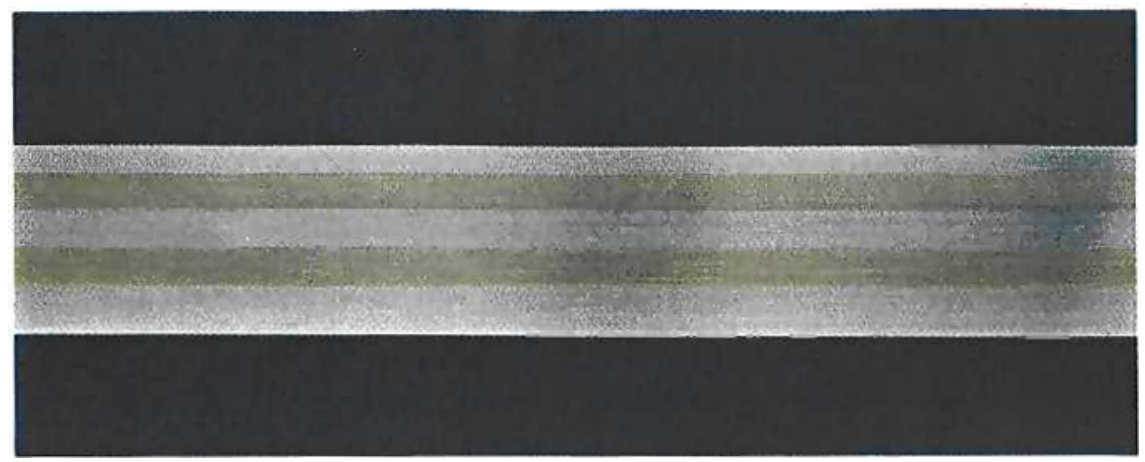

and on the number of target atoms which are removed by a single ion impact (the specific sputtering rate). It is only possible to increase the ion density to a certain extent when carrying out direct current sputtering using a self-sustained discharge. As soon as a limiting current of a few amperes is exceeded, the discharge transforms to an uncontrollable arc which wanders about the target surface in a random manner. It is, therefore, more satisfactory to use methods other than increasing the gas pressure to raise the ion density, such as the use of an auxiliary thermionic cathode or the application of a radiofrequency alternating current discharge.

The high frequency method is preferable as it is more versatile and allows of higher energy densities in the discharge. In principle, ionised plasma can be produced by an electrodeless circular discharge, the induction coil remaining outside the glass or ceramic vacuum chamber. An interesting variation of the technique is to fabricate the plasma generating coil from the target metal and place it inside the vacuum chamber (German Patent 1,515,296.1). An energy output of $20 \mathrm{~kW}$ can be readily obtained in a volume of 0.3 litre using a cylindrical coil, or over an area of $200 \mathrm{~cm}^{2}$ using a rectangular or circular flat coil. The bombardment resulting from such high power inputs generates a high temperature in the coil and can easily lead to melting. It is, therefore, necessary to provide efficient water cooling, for example, a water-cooled copper tube covered with the alloy to be sputtered. It is essential to ensure good thermal contact between the copper and the alloy.

Efficient cooling is also necessary to prevent thermal evaporation being superimposed on the sputtering process as this would lead to fractionation of the components. It has been observed that in the case of a pale yellow gold-silver-copper alloy those areas which are insufficiently cooled tend to assume a more reddish colour after sputtering because silver (the component with the highest vapour pressure) is the first metal to evaporate leaving the alloy with a smaller silver content in the overheated areas. If the cooling is adequate, the deposited film will have the same composition as the original alloy. This fact can be checked by X-ray fluorescence analysis. As a general rule, it is advisable to use vacuum melted alloys as starting materials in order to avoid spitting caused by dissolved gases.

Figure 1 shows a cylindrical coil used for the plasma discharge. With high energy inputs, the colour of the discharge is characteristic of the metal of the coil. The discharge can be maintained at pressures down to $10^{-4}$ torr. Sputtering rates of $1 \mu \mathrm{m}$ per minute can be achieved without difficulty.

Figure 2 shows a production plant for coating flat spring strip. The range of alloys which have been tested include gold-palladium, gold-nickel, gold-silver, and gold-silver-copper, all of which form solid solutions. It is also possible to produce heterogeneous mixtures such as gold and molybdenum or gold and tungsten which are of interest for certain types of switchgear contacts.

Practical tests have shown that the physical and chemical properties of the alloy coatings come up to expectation in respect of hardness, abrasion resistance, and conductivity.

\section{Gold Plating in Computer Memory Elements}

Wires having an electrodeposited film of nickeliron alloy form the essential feature of computer memory elements, but their magnetic properties are critically dependent on the structure and surface finish of the underlying copper deposit. Their performance has now been found to be improved by the electrodeposition of gold between the copper and the nickeliron layers. During an investigation by F. E. Luborsky, M. W. Breiter and B. J. Drummond of General Electric Corporate Research and Development ( $\mathcal{F}$. Electrochem. Soc., 1972, 119, (1), 92) the deposition of gold at very low current densities on to a rough and coarsegrained copper deposit produced islands of gold by selective deposition on to the high points of the copper surface, and performance was found to be related to a specific structure of these islands. 